\title{
Clinical Significance of Serum Chitotriosidase Level in Anti-MDA5 Antibody-positive Dermatomyositis-associated Interstitial Lung Disease
}

\author{
Tomoyuki Fujisawa (D), Hironao Hozumi (D), Hideki Yasui, Yuzo Suzuki, Masato Karayama, \\ Kazuki Furuhashi, Noriyuki Enomoto, Yutaro Nakamura, Naoki Inui, and Takafumi Suda
}

\begin{abstract}
Objective. To assess prognostic factors of antimelanoma differentiation-associated gene 5 antibody (anti-MDA5)-positive dermatomyositis/clinically amyopathic DM-associated interstitial lung disease (DM/CADM-ILD) and evaluate the use of serum chitotriosidase, a marker for macrophage activation, as a potential biomarker in anti-MDA5-positive DM/CADM-ILD.

Methods. This retrospective study included 30 patients with anti-MDA5-positive DM/CADM-ILD. The clinical characteristics and laboratory findings at the time of diagnosis were analyzed. Serum chitotriosidase levels were measured in the 30 patients, in 21 healthy controls, and in 25 patients with anti-aminoacyl- tRNA synthetase antibody-positive (anti-ARS)-polymyositis (PM)/DM/CADM-ILD, and the potential of serum chitotriosidase as a prognostic biomarker in anti-MDA5-positive DM/CADM-ILD was assessed.

Results. The median serum chitotriosidase level in patients with anti-MDA5-positive DM/CADM-ILD was $17.3 \mathrm{ng} / \mathrm{ml}$, which was higher than that in healthy controls and anti-ARS$\mathrm{PM} / \mathrm{DM} / \mathrm{CADM}-\mathrm{ILD}(2.0$ and $8.9 \mathrm{ng} / \mathrm{ml}$, respectively). Of the 30 patients, 10 died of respiratory failure associated with DM/CADM-ILD deterioration. Cox hazard analysis demonstrated that higher serum chitotriosidase level and lower $\mathrm{PaO}_{2}$ value were significant predictors of a poor outcome. Using optimal cutoff levels according to receiver-operating characteristic curve analyses, chitotriosidase $\geq 23.5 \mathrm{ng} / \mathrm{ml}$, ferritin $\geq 800 \mathrm{ng} / \mathrm{ml}$, and Krebs von den Lungen-6 $\geq 720 \mathrm{U} / \mathrm{ml}$ were significantly associated with a poor prognosis. Serum chitotriosidase levels were negatively correlated with $\mathrm{PaO}_{2}$ and percentage predicted forced vital capacity. The survival rate was significantly poorer in patients with high chitotriosidase levels $(\geq 23.5 \mathrm{ng} / \mathrm{ml})$ than in those with low chitotriosidase levels $(<23.5 \mathrm{ng} / \mathrm{ml})$.

Conclusion. Serum chitotriosidase may be a potential biomarker for predicting a poor prognosis in patients with anti-MDA5-positive DM/CADM-ILD. (First Release May 15 2019; J Rheumatol 2019;46:935-42; doi:10.3899/jrheum.180825)
\end{abstract}

Key Indexing Terms: DERMATOMYOSITIS CHITOTRIOSIDASE

\section{INTERSTITIAL LUNG DISEASE PROGNOSTIC FACTORS ANTI-MDA5 ANTIBODY FERRITIN}

From the Second Division, Department of Internal Medicine, and the Department of Clinical Pharmacology and Therapeutics, Hamamatsu University School of Medicine, Hamamatsu, Japan.

T. Fujisawa, MD, PhD, Second Division, Department of Internal Medicine, Hamamatsu University School of Medicine; H. Hozumi, MD, PhD, Second Division, Department of Internal Medicine, Hamamatsu University School of Medicine; H. Yasui, MD, PhD, Second Division, Department of Internal Medicine, Hamamatsu University School of Medicine; Y. Suzuki, MD, PhD, Second Division, Department of Internal Medicine, Hamamatsu University School of Medicine; M. Karayama, MD, PhD, Second Division, Department of Internal Medicine, Hamamatsu University School of Medicine; K. Furuhashi, MD, PhD, Second Division, Department of Internal Medicine, Hamamatsu University School of Medicine; $N$. Enomoto, MD, PhD, Second Division, Department of Internal Medicine, Hamamatsu University School of Medicine; Y. Nakamura, MD, PhD, Second Division, Department of Internal Medicine, Hamamatsu University School of Medicine; N. Inui, MD, PhD, Department of Clinical

Pharmacology and Therapeutics, Hamamatsu University School of Medicine; T. Suda, MD, PhD, Second Division, Department of Internal Medicine, Hamamatsu University School of Medicine.

Address correspondence to Dr. T. Fujisawa, 1-20-1 Handayama Higashi-ku, Hamamatsu 431-3192, Japan.E-mail: fujisawa@hama-med.ac.jp Accepted for publication November 15, 2018.
Polymyositis (PM) and dermatomyositis (DM) are systemic autoimmune diseases affecting the skeletal muscles, skin, and other organs, such as the lungs and joints ${ }^{1}$. Clinically amyopathic dermatomyositis (CADM) is a distinct subgroup of DM that involves a rash typical of classic DM, but with little or no evidence of muscular manifestations ${ }^{2,3}$. Patients with PM, DM, or CADM frequently show interstitial lung disease (ILD) as a pulmonary complication. The clinical course of ILD varies among patients ${ }^{4,5,6}$; however, this condition has been reported to be a major cause of morbidity and mortality $3,7,8,9,10$.

Recent studies have demonstrated the importance of assessing serum myositis-specific antibodies (MSA) for predicting the clinical course and prognosis in patients with $\mathrm{PM}$, DM, or CADM ${ }^{11,12}$. Antimelanoma differentiationassociated gene 5 antibody (anti-MDA5) is an MSA found in $20 \%-35 \%$ of patients with DM or CADM ${ }^{13,14,15}$, and the detection of this antibody has been shown to be related to a

Personal non-commercial use only. The Journal of Rheumatology Copyright (c) 2019. All rights reserved. 
high ILD incidence and a poor prognosis ${ }^{14,16,17,18,19}$. We previously evaluated the MSA status in 60 patients with $\mathrm{PM} / \mathrm{DM} / \mathrm{CADM}$-associated ILD and reported that $25 \%$ of the patients were positive for anti-MDA5 and that the seropositive status of anti-MDA5 was significantly associated with a poor prognosis ${ }^{17}$. Additionally, the major cause of death in anti-MDA5-positive patients was respiratory failure associated with acute/subacute deterioration of ILD within 6 months (90-day survival rate of $66.7 \%$ among the anti-MDA5-positive patients). Considering the poor prognosis of patients with anti-MDA5-positive DM/CADMassociated ILD (DM/CADM-ILD), the prognostic factors and serum biomarkers of disease severity should be evaluated for appropriate management and treatment in clinical practice. However, the factors and biomarkers for predicting a poor outcome in patients with anti-MDA5-positive DM/CADM-ILD remain to be determined.

Chitotriosidase, a member of the glycosyl hydrolase family, is a chitinase in humans that catalyzes the hydrolysis of both chitin and chitin-like substrates ${ }^{20,21}$. An increase in chitotriosidase activity was originally noted in Gaucher disease, a genetic disorder in which lipid accumulation in macrophages occurs in certain organs (e.g., spleen, liver, lungs, kidneys, and brain $)^{20,22}$. Chitotriosidase is mainly produced by activated macrophages and neutrophils under inflammatory conditions ${ }^{20,21,22}$, and it plays an important role in infectious diseases (e.g., fungal infections) as an innate immune response component against chitin present in the cell structure of pathogens. Chitotriosidase is considered a marker for macrophage activation and differentiation. Studies have demonstrated that serum chitotriosidase is a potential biomarker for monitoring several lung diseases, such as tuberculosis, sarcoidosis, chronic obstructive pulmonary disease, and asthma $23,24,25,26,27$.

Anti-MDA5-positive DM/CADM can occasionally cause macrophage activation syndrome (MAS). In fatal cases of anti-MDA5-positive CADM-related rapidly progressive ILD, systemic activation of macrophages is observed in many organs, and it might be related to the pathogenesis ${ }^{28}$. Serum chitotriosidase has been highlighted as an indicator of macrophage activation and a potential biomarker; however, the clinical significance of the serum chitotriosidase level in patients with anti-MDA5-positive DM/CADM-ILD remains unclear. In our present study, we assessed the clinical features and prognostic factors of anti-MDA5-positive DM/CADM-ILD and evaluated the use of serum chitotriosidase as a potential biomarker in patients with anti-MDA5positive DM/CADM-ILD.

\section{MATERIALS AND METHODS}

Subjects. This retrospective study included patients diagnosed with anti-MDA5-positive DM/CADM-ILD at Hamamatsu University Hospital and its affiliated hospitals in Japan between 2000 and 2017. DM was diagnosed according to the Bohan and Peter criteria ${ }^{29}$, as described previously $^{4,6}$. Patients with definite or probable DM were included. CADM was diagnosed according to the presence of a rash characteristic of DM and absence of clinical evidence of muscular disorders along with little or no increase in the serum creatine kinase level, as described previously ${ }^{5,6,30}$. To evaluate serum chitotriosidase levels, the study enrolled 21 age- and sex-matched healthy controls and 25 patients with anti-aminoacyl-tRNA synthetase antibodies (anti-ARS)-positive PM/DM/CADM-ILD (3 PM, 9 DM, 13 CADM). This study was approved by the Institutional Review Board of Hamamatsu University School of Medicine (approval number: E15-062)

Evaluation of ILD. ILD was diagnosed according to respiratory symptom presence, physical examination findings, chest high-resolution computed tomography (HRCT) findings, and pulmonary function test results. ILD was classified into the following 3 types: acute, subacute, and chronic. Acute ILD was defined as rapidly progressive ILD showing acute worsening or development of dyspnea with a new widespread alveolar abnormality on chest HRCT within 1 month from the onset of respiratory symptoms or the initial visit ${ }^{17,31}$. Subacute ILD was defined as progressive ILD with deterioration in 1-3 months ${ }^{5,6,17,32}$. Chronic ILD was defined as stable or slowly progressive ILD presenting with gradual deterioration over a period longer than 3 months $\mathrm{s}^{5,6,17,32}$. ILD deterioration was assessed according to the modified version of the International Consensus Statement of idiopathic pulmonary fibrosis of the American Thoracic Society ${ }^{33,34}$. It was defined as the presence of 2 or more of the following findings during the followup period: (1) symptomatic exacerbation (e.g., dyspnea upon exertion); (2) an increase in opacity on chest HRCT; and (3) $>10 \%$ decrease in the percentage predicted forced vital capacity $(\% \mathrm{FVC})$ or $>10 \mathrm{mmHg}$ decrease in arterial oxygen tension $\left(\mathrm{PaO}_{2}\right)$.

Data collection, measurement of anti-MDA5 titers, and measurement of serum chitotriosidase levels. Clinical data, including symptoms, physical findings, laboratory findings, and pulmonary function test results, were obtained from the medical records collected at the first encounter that led to the diagnoses of ILD and DM/CADM. Stored serum samples collected at the initial diagnosis of DM/CADM-ILD were used to measure anti-MDA5 titers and serum chitotriosidase levels. Anti-MDA5 titers were measured using ELISA ${ }^{15}$, and serum chitotriosidase levels were determined using chitotriosidase ELISA (CircuLex Human Chitotriosidase ELISA Kit; MBL), according to the manufacturer's instructions.

Statistical analysis. We used either the chi-square test or Fisher's exact test (as appropriate for the sample size) for 2-group comparisons involving binary data. Comparisons involving continuous data were performed using the Mann-Whitney U test. Receiver-operating characteristic (ROC) curve analyses were performed to identify the optimal cutoff values of serum markers [ferritin, chitotriosidase, and Krebs von den Lungen-6 (KL-6)] for predicting a poor outcome. The cutoff value of each serum marker was decided as the point that has the highest value of sensitivity + specificity 1 (Youden's index). Correlations between serum chitotriosidase levels and clinical variables were evaluated using the Spearman correlation coefficients test. Cox proportional hazard models were used to identify the variables associated with survival. Akaike information criterion (AIC) was used to compare relative abilities to predict poor outcome. The cumulative survival rate was calculated by using the Kaplan-Meier method. The log-rank test was used to compare the survival rate between patient groups. All statistical analyses were performed using commercially available software programs (JMP version 9.0: SAS Institute Inc., and R version 3.4.3: The R Foundation for Statistical Computing). A p value $<0.05$ was considered statistically significant.

\section{RESULTS}

Baseline characteristics. The study included 30 patients with anti-MDA5-positive DM/CADM-ILD. Of these 30 patients, $13(43 \%)$ had DM-ILD and 17 (57\%) had CADM-ILD. The clinical characteristics of the enrolled patients are presented in Table 1. The median patient age was 54 years, and 23

Personal non-commercial use only. The Journal of Rheumatology Copyright $\odot$ (2019. All rights reserved 
Table 1. Clinical characteristics of study patients with anti-MDA5-positive DM/CADM-ILD.

\begin{tabular}{lc}
\hline Characteristics & $\mathrm{n}=30$ \\
\hline Median age, yrs & $54.0(31-80)$ \\
Female & $23(77)$ \\
Median observation period, yrs & $1.01(0.02-18.8)$ \\
Smoking status & \\
Never/former/current & $18(60) / 8(27) / 4(13)$ \\
Myositis diagnosis & \\
DM/CADM & $13(43) / 17(57)$ \\
ILD form & \\
Acute & $10(33)$ \\
Subacute & $18(60)$ \\
Chronic & $2(7)$ \\
Laboratory data & \\
Anti-MDA5 antibody, U/ml & $185(56-285)$ \\
Ferritin, ng/ml & $664(107-12,701)$ \\
Chitotriosidase, ng/ml & $17.3(0-53.2)$ \\
CPK, IU/l & $110(20-1790)$ \\
Aldolase, U/l & $6.7(3.0-27.2)$ \\
KL-6, U/ml & $739(249-2450)$ \\
SP-D, ng/ml & $41.7(17.1-228)$ \\
Pulmonary function & \\
PaO, Torr & $69.0(42.6-109)$ \\
$\%$ FVC, $\%$ & $72.3(36.6-125.5)^{*}$ \\
Mortality & $10(33)$ \\
\hline
\end{tabular}

*Four patients in fatal cases could not undergo pulmonary function tests. Data are expressed as number (percentage) or median (range). DM: dermatomyositis; CADM: clinically amyopathic dermatomyositis; ILD: interstitial lung disease; anti-MDA5 antibody: antimelanoma differentiation-associated gene 5 antibody; CPK: creatine phosphokinase; KL-6: Krebs von den Lungen-6; SP-D: surfactant protein D; FVC: forced vital capacity.
(77\%) of the 30 patients were women. Of the 30 patients, 10 (33\%) had acute ILD, 18 (60\%) had subacute ILD, and 2 (7\%) had chronic ILD. The median serum ferritin and KL-6 levels were elevated [ferritin: $664 \mathrm{ng} / \mathrm{ml}$ (reference range: male, $13-277 \mathrm{ng} / \mathrm{ml}$; female, 5-153 ng/ml); KL-6: $739 \mathrm{U} / \mathrm{ml}$ (reference range: $\leq 500 \mathrm{U} / \mathrm{ml}$ )]. The median (range) serum chitotriosidase levels in the patients with anti-MDA5-positive DM/CADM-ILD were significantly higher than those in healthy controls $[17.3(0-53.2 \mathrm{ng} / \mathrm{ml})$ vs $2.0(1.6-27.6$ $\mathrm{ng} / \mathrm{ml}), \mathrm{p}=0.0013]$ and relatively higher than those in patients with anti-ARS-positive PM/DM/CADM-ILD [8.9 $(1.9-31.2 \mathrm{ng} / \mathrm{ml}), \mathrm{p}=0.36$; Supplementary Figure 1, available with the online version of this article]. The median $\mathrm{PaO}_{2}$ and $\% \mathrm{FVC}$ values were relatively low. Of the 30 patients, 10 died of respiratory failure associated with DM/CADM-ILD deterioration within 4 months after diagnosis.

Comparisons of the clinical findings and treatments between survivors and nonsurvivors. Comparisons of the clinical findings between patients who survived (survivor group, $\mathrm{n}=20$ ) and those who died of respiratory failure (nonsurvivor group, $\mathrm{n}=10$ ) are presented in Table 2 . The median patient age and patient sex were not different between the groups. In the survivor group, 1 patient (5\%) had acute ILD, 17 (85\%) had subacute ILD, and $2(10 \%)$ had chronic ILD. In the nonsurvivor group, 9 patients $(90 \%)$ had acute ILD and 1 $(10 \%)$ had subacute ILD. No patient from the nonsurvivor group had chronic ILD. Regarding laboratory data, serum ferritin, chitotriosidase, and KL-6 levels were significantly

Table 2. Comparisons of the clinical findings between survivors and nonsurvivors.

\begin{tabular}{lccc}
\hline Characteristics & Survivor, $\mathrm{n}=20$ & Nonsurvivor, $\mathrm{n}=10$ & $\mathrm{p}$ \\
\hline Median age, yrs & $54.5(31-69)$ & $54(32-80)$ & 0.48 \\
Female & $16(80)$ & $7(70)$ & 0.55 \\
Median observation period, yrs & $2.67(0.33-18.8)$ & $0.14(0.02-0.28)$ & $<0.001$ \\
Myositis diagnosis & & & 0.29 \\
DM/CADM & $10(50) / 10(50)$ & $3(30) / 7(70)$ & $<0.001$ \\
ILD form, n (\%) & $1(5)$ & & \\
Acute & $17(85)$ & $9(90)$ & \\
Subacute & $2(10)$ & 0 & \\
Chronic & & & \\
Laboratory data & $183(113-285)$ & $213(56-264)$ & 0.16 \\
Anti-MDA5 antibody, U/ml & $511(107-1480)$ & $1078(197-12,701)$ & 0.022 \\
Ferritin, ng/ml & $12.4(0-39.8)$ & $27.8(3.8-53.2)$ & 0.017 \\
Chitotriosidase, ng/ml & $95(20-1498)$ & $133(24-1790)$ & 0.63 \\
CPK, IU/l & $6.15(3.1-12.7)$ & $8.95(3.0-27.2)$ & 0.26 \\
Aldolase, U/l & $660(249-2450)$ & $1026(297-2230)$ & 0.039 \\
KL-6, U/ml & $56.6(17.1-137)$ & $30.6(17.2-338)$ & 0.17 \\
SP-D, ng/ml & & & \\
Pulmonary function & $75.0(57.9-109)$ & $63.3(42.6-69.4)$ & 0.004 \\
PaO, Torr & $79.3(36.6-125.5)$ & $51.3(38.1-82.8)^{*}$ & 0.021 \\
\%FVC & & & \\
\hline
\end{tabular}

*Four patients in the nonsurvivor group could not undergo pulmonary function tests. Data are expressed as number (percentage) or median (range). DM: dermatomyositis; CADM: clinically amyopathic dermatomyositis; ILD: interstitial lung disease; anti-MDA5 antibody: antimelanoma differentiation-associated gene 5 antibody; CPK: creatine phosphokinase; KL-6: Krebs von den Lungen-6; SP-D: surfactant protein D; FVC: forced vital capacity. 
higher in the nonsurvivor group than in the survivor group $(p=0.022, p=0.017$, and $p=0.039$, respectively). However, the creatine phosphokinase and aldolase levels were not different between the groups. Additionally, the surfactant protein $\mathrm{D}$ levels were almost identical between the groups. The $\mathrm{PaO}_{2}$ and $\% \mathrm{FVC}$ values were significantly lower in the nonsurvivor group than in the survivor group $(p=0.004$ and $\mathrm{p}=0.021$, respectively). However, 4 patients in the nonsurvivor group could not undergo pulmonary function tests.

Comparisons of treatments between the survivor and nonsurvivor groups are presented in Supplementary Table 1, available with the online version of this article. All patients in both groups received corticosteroids and immunosuppressive agents. The initial dose of prednisolone was comparable between the groups; however, the frequency of intravenous methylprednisolone pulse therapy (500-1000 $\mathrm{mg} /$ day for 3 days) was significantly higher in the nonsurvivor group than in the survivor group $(\mathrm{p}=0.020)$. Combination therapy, including corticosteroids, calcineurin inhibitors (cyclosporine or tacrolimus), and intravenous cyclophosphamide (IV CYC), was administered to 8 patients $(80 \%)$ from the nonsurvivor group and 1 patient $(5 \%)$ from the survivor group $(\mathrm{p}<0.0001)$. IV immunoglobulins were administered to 7 patients (70\%) from the nonsurvivor group and 3 patients $(16 \%)$ from the survivor group $(\mathrm{p}=0.0035)$.

Cutoff levels of serum markers and correlations between serum chitotriosidase levels and clinical variables. ROC curve analyses were performed for ferritin, chitotriosidase, and KL-6 (Supplementary Figure 2, available with the online version of this article). The area under the curve (AUC) of serum ferritin for predicting a poor outcome was 0.760 . Using $800 \mathrm{ng} / \mathrm{ml}$ as the cutoff level of serum ferritin, the sensitivity and specificity were $80.0 \%$ and $70.0 \%$, respectively (Supplementary Figure 2A). The AUC of serum chitotriosidase for predicting a poor outcome was 0.778 . Using $23.5 \mathrm{ng} / \mathrm{ml}$ as the cutoff level of serum chitotriosidase, the sensitivity and specificity were $70.0 \%$ and $80.0 \%$, respectively (Supplementary Figure 2B). The AUC of serum KL-6 for predicting a poor outcome was 0.733 . Using $720 \mathrm{U} / \mathrm{ml}$ as the cutoff level of serum KL-6, the sensitivity and specificity were $90.0 \%$ and $55.0 \%$, respectively (Supplementary Figure $2 \mathrm{C})$. The AUC of serum chitotriosidase was larger than the AUC of serum ferritin and KL-6.

Correlations between serum chitotriosidase levels and conventional clinical variables are presented in Table 3 . Serum chitotriosidase levels showed significant negative correlations with $\mathrm{PaO}_{2}(\mathrm{r}=-0.52, \mathrm{p}=0.005)$ and $\% \mathrm{FVC}$ $(\mathrm{r}=-0.43, \mathrm{p}=0.028)$.

Survival analysis. The results of Cox proportional hazard regression analysis are shown in Table 4. In univariate analysis, acute ILD, high serum chitotriosidase levels, and low $\mathrm{PaO}_{2}$ values were significantly associated with a poor outcome in patients with anti-MDA5-positive DM/CADM-ILD. Using the optimal cutoff levels, serum ferritin $(\geq 800 \mathrm{ng} / \mathrm{ml}$ ),
Table 3. Correlations between serum chitotriosidase levels and clinical variables.

\begin{tabular}{lcc}
\hline Variables & $\mathrm{r}$ & $\mathrm{p}$ \\
\hline Ferritin, ng/ml & 0.14 & 0.46 \\
$\mathrm{CPK}, \mathrm{IU} / \mathrm{l}$ & -0.07 & 0.71 \\
$\mathrm{Aldolase}, \mathrm{U} / \mathrm{K}$ & 0.10 & 0.58 \\
$\mathrm{KL}-6, \mathrm{U} / \mathrm{ml}$ & 0.30 & 0.11 \\
$\mathrm{SP}-\mathrm{D}, \mathrm{ng} / \mathrm{ml}$ & -0.21 & 0.27 \\
$\mathrm{PaO}, \mathrm{Torr}$ & -0.52 & 0.005 \\
$\% \mathrm{FVC}, \%$ & -0.43 & 0.028 \\
\hline
\end{tabular}

CPK: creatine phosphokinase; KL-6: Krebs von den Lungen-6, SP-D: surfactant protein D; FVC: forced vital capacity.

chitotriosidase ( $\geq 23.5 \mathrm{ng} / \mathrm{ml})$, and KL-6 ( $\geq 720 \mathrm{U} / \mathrm{ml}$ ) were significantly associated with a poor prognosis. Because serum markers can be evaluated noninvasively, even when patients have severe symptoms (e.g., respiratory failure), we focused on serum markers, ferritin, chitotriosidase, and KL-6. We performed separate multivariate Cox proportional hazard regression analyses of each serum marker, adjusted by age and sex. Multivariate Cox analyses demonstrated that higher serum chitotriosidase levels and higher serum ferritin levels, adjusted by age and sex, were significantly associated with a poor prognosis, and serum KL-6 levels were not (Table 4). Serum ferritin ( $\geq 800 \mathrm{ng} / \mathrm{ml})$, chitotriosidase $(\geq 23.5 \mathrm{ng} / \mathrm{ml})$, and KL-6 ( $\geq 720 \mathrm{U} / \mathrm{ml})$, adjusted by age and sex, were also associated with a poor prognosis (Table 4). To compare the predictive abilities of each model we evaluated the respective AIC indices. The AIC index of the chitotriosidase model (chitotriosidase, age, and sex) was 60.57 , lower than the ferritin model (ferritin, age, and sex) and the KL-6 model (KL-6, age, and sex; 62.88 and 65.42, respectively). Thus, a higher serum chitotriosidase level is a better prognostic indicator in patients with anti-MDA5-positive DM/CADM-ILD. We performed survival analysis using the optimal cutoff level of serum chitotriosidase. The 30 study patients were divided into the following 2 groups according to the cutoff level of serum chitotriosidase: chitotriosidase ${ }^{\text {high }}(\geq 23.5 \mathrm{ng} / \mathrm{ml}$, $\mathrm{n}=11)$ and chitotriosidase ${ }^{\text {low }}(<23.5 \mathrm{ng} / \mathrm{ml}, \mathrm{n}=19)$. KaplanMeier survival curves are presented in Figure 1. The mortality rate was significantly higher in the chitotriosidase $^{\text {high }}$ group than in the chitotriosidase ${ }^{\text {low }}$ group $(60 \%$ vs $20 \%, \mathrm{p}=0.003)$.

\section{DISCUSSION}

In our study, we evaluated the clinical significance of serum chitotriosidase as a potential biomarker in patients with anti-MDA5-positive DM/CADM-ILD. We found that the serum chitotriosidase level was significantly higher in patients with DM/CADM-ILD than in healthy controls. In particular, the serum chitotriosidase level was higher in patients with DM/CADM-ILD who had a fatal outcome than in surviving patients. A high serum chitotriosidase level and

Personal non-commercial use only. The Journal of Rheumatology Copyright (C) 2019. All rights reserved. 
Table 4. Cox proportional hazard regression analysis of mortality.

\begin{tabular}{lccc}
\hline Analytical Data & HR & $95 \% \mathrm{CI}$ & $\mathrm{p}$ \\
\hline Univariate analysis & & & \\
Age, yrs & 1.04 & $0.979-1.11$ & 0.21 \\
Female & 0.66 & $0.181-3.05$ & 0.55 \\
DM vs CADM & 0.48 & $0.103-1.73$ & 0.27 \\
Acute ILD & 34.7 & $6.34-647$ & $<0.0001$ \\
Ferritin, ng/ml & 1.00 & $0.999-1.000$ & 0.20 \\
Chitotriosidase, ng/ml & 1.06 & $1.01-1.10$ & 0.01 \\
CPK, IU/l & 1.00 & $0.999-1.001$ & 0.79 \\
Aldolase, U/l & 1.07 & $0.968-1.16$ & 0.17 \\
KL-6, U/ml & 1.00 & $0.999-1.001$ & 0.12 \\
SP-D, ng/ml & 1.00 & $0.988-1.02$ & 0.61 \\
PaO, Torr & 0.87 & $0.783-0.946$ & 0.0004 \\
Ferritin $\geq 800 \mathrm{ng} / \mathrm{ml}$ & 5.42 & $1.35-35.9$ & 0.015 \\
Chitotriosidase $\geq 23.5 \mathrm{ng} / \mathrm{ml}$ & 6.09 & $1.68-28.5$ & 0.006 \\
KL-6 $\geq 720 \mathrm{U} / \mathrm{ml}$ & 7.62 & $1.42-140.9$ & 0.014 \\
Multivariate analysis, adjusted for age and sex & & & \\
Ferritin, ng/ml & 1.00 & $1.000-1.001$ & 0.031 \\
Chitotriosidase, ng/ml & 1.06 & $1.02-1.11$ & 0.008 \\
KL-6, U/ml & 1.00 & $0.999-1.001$ & 0.15 \\
Ferritin $\geq 800 \mathrm{ng} / \mathrm{ml}$ & 6.06 & $1.45-41.4$ & 0.012 \\
Chitotriosidase $\geq 23.5 \mathrm{ng} / \mathrm{ml}$ & 6.06 & $1.65-28.5$ & 0.007 \\
KL-6 $\geq 720 \mathrm{U} / \mathrm{ml}$ & 9.19 & $1.60-174$ & 0.01 \\
\hline
\end{tabular}

DM: dermatomyositis; CADM: clinically amyopathic dermatomyositis; ILD: interstitial lung disease; CPK: creatine phosphokinase; KL-6: Krebs von den Lungen-6, SP-D: surfactant protein D.

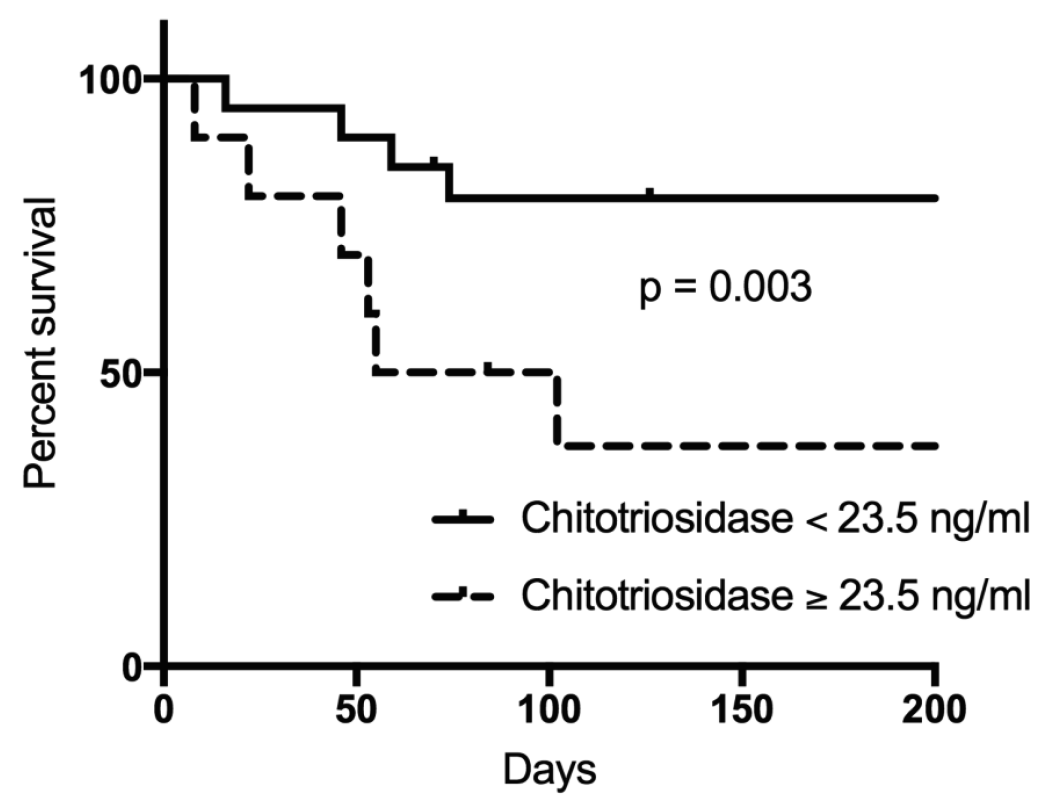

Figure 1. Survival curves for the chitotriosidase ${ }^{\text {high }}$ group and chitotriosidase ${ }^{\text {low }}$ group. The 30 study patients were divided into the following 2 groups according to the cutoff level of serum chitotriosidase: chitotriosidase ${ }^{\text {high }}(\geq 23.5 \mathrm{ng} / \mathrm{ml}, \mathrm{n}=11$, dashed line $)$ and chitotriosidase $^{\text {low }}(<23.5 \mathrm{ng} / \mathrm{ml}, \mathrm{n}=19$, solid line $)$. The mortality rate is significantly higher in the chitotriosidase $^{\text {high }}$ group than in the chitotriosidase ${ }^{\text {low }}$ group $(60 \%$ vs $20 \%, \mathrm{p}=0.003)$.

low $\mathrm{PaO}_{2}$ value at the time of diagnosis were significant predictors of a poor outcome in patients with anti-MDA5positive DM/CADM-ILD. Using optimal cutoff levels according to ROC curve analyses, we found that chitotriosidase $\geq 23.5 \mathrm{ng} / \mathrm{ml}$, ferritin $\geq 800 \mathrm{ng} / \mathrm{ml}$, and KL-6 $\geq 720$ $\mathrm{U} / \mathrm{ml}$ were significantly associated with a poor prognosis.

Personal non-commercial use only. The Journal of Rheumatology Copyright @ 2019 . All rights reserved. 
The AUC was the largest for serum chitotriosidase among the 3 markers. Moreover, serum chitotriosidase levels were correlated with oxygenation impairment and lung function. The survival rate was poorer in patients with high chitotriosidase levels $(\geq 23.5 \mathrm{ng} / \mathrm{ml}$ ) than in those with low chitotriosidase levels $(<23.5 \mathrm{ng} / \mathrm{ml})$. These findings suggest the clinical significance of serum chitotriosidase as a prognostic biomarker in patients with anti-MDA5-positive DM/CADM-ILD.

To our knowledge, this is the first study to show that the serum chitotriosidase level was higher in patients with anti-MDA5-positive DM/CADM-ILD, particularly those with a fatal outcome, than in healthy controls and in anti-ARS-positive PM/DM/CADM-ILD, and that the serum chitotriosidase level was associated with a poor prognosis in anti-MDA5-positive DM/CADM-ILD. Chitotriosidase is produced by monocyte-derived macrophages, lung macrophages, neutrophils, and epithelial cells in the lungs and intestine ${ }^{35,36,37}$. Its expression is upregulated by Toll-like receptor stimulation, interferon (IFN)- $\gamma$, tumor necrosis factor (TNF)- $\alpha$, and granulocyte-macrophage colony-stimulating factor (GM-CSF) ${ }^{35,38}$. Anti-MDA5-positive DM/ CADM is partially considered a type of MAS, in which uncontrolled activation of macrophages and $\mathrm{T}$ lymphocytes and marked increases in the levels of circulating cytokines [including TNF- $\alpha$, interleukin (IL)-1 $\beta$, IL-6, IL-18, IFN- $\beta$, and GM-CSF] are involved in the pathogenesis ${ }^{39,40}$. Elevated serum chitotriosidase levels might reflect the pathophysiology of anti-MDA5-positive DM/CADM-ILD, including the excessive production of proinflammatory cytokines and activation of alveolar macrophages and neutrophils in the lungs. Further investigations involving lung biopsy or bronchoalveolar lavage are required to elucidate the underlying pathophysiology of anti-MDA5-positive DM/CADM-ILD.

Serum chitotriosidase levels might reflect disease severity in patients with anti-MDA5-positive DM/CADM-ILD. Indeed, the present study demonstrated that serum chitotriosidase levels were negatively correlated with $\mathrm{PaO}_{2}$ and $\% \mathrm{FVC}$ in patients with anti-MDA5-positive DM/CADM-ILD. Lee, et al showed that plasma chitotriosidase activity and chitotriosidase protein expression in lung specimens were significantly higher in patients with systemic sclerosisassociated ILD than in healthy controls and that chitotriosidase activity was negatively correlated with $\% \mathrm{FVC}^{37}$. Additionally, they used animal models and demonstrated that bleomycin-induced pulmonary fibrosis was significantly reduced in chitotriosidase null mice and enhanced in chitotriosidase overexpression transgenic mice, indicating that chitotriosidase enhanced disease severity and could be a therapeutic target for pulmonary fibrosis. Interestingly, a study involving a bleomycin-induced lung injury model, using human MUC1-expressing mice, demonstrated that increased serum KL-6 levels were associated with the degree of lung injury and disruption of the alveolar-capillary barrier ${ }^{41}$. In our present study, serum KL-6 levels, as well as serum chitotriosidase levels and ferritin levels, were significantly higher in the nonsurvivor group than in the survivor group. This suggests that KL-6 levels reflect the extent of lung injury in anti-MDA5-positive DM/CADM-ILD. Given that an elevated KL-6 level may reflect disease severity for both anti-MDA5-positive DM/CADM-ILD and bleomycin-induced lung injury, partial similarity of pathological condition between anti-MDA5-positive DM/CADM-ILD and bleomycin-induced lung injury might exist. Further studies are necessary to determine the detailed pathological conditions in anti-MDA5-positive DM/CADM-ILD.

Few studies have evaluated potential biomarkers in patients with anti-MDA5-positive DM/CADM-ILD ${ }^{16,42}$. Gono, et al showed that serum ferritin levels $\geq 828 \mathrm{ng} / \mathrm{ml}$ and alveolar-arterial oxygen difference $\geq 32 \mathrm{mmHg}$ were associated with a poor prognosis in rapidly progressive ILD patients with anti-MDA5-positive $\mathrm{DM}^{16}$. Consistent with these findings, our study demonstrated that serum ferritin levels $\geq 800 \mathrm{ng} / \mathrm{ml}$, a low $\mathrm{PaO}_{2}$ value, and a high serum chitotriosidase level were significantly associated with a poor prognosis in patients with anti-MDA5-positive DM/CADM-ILD. Serum ferritin is a key biomarker of MAS, and thus, high serum ferritin levels might be attributable to the systemic activation of macrophages, similar to high chitotriosidase levels, which might be a key feature in the pathogenesis of anti-MDA5positive DM/CADM-ILD.

In our study, serum chitotriosidase levels showed no significant correlation with serum ferritin levels in patients with anti-MDA5-positive DM/CADM-ILD (Table 3). Cellular sources and activators of chitotriosidase may not be identical to those of ferritin, although both are produced by activated macrophage. Chitotriosidase is produced by macrophages, neutrophils, and epithelial cells under inflammatory conditions ${ }^{35,36,37}$, while ferritin can be secreted by various cell types such as lymphocytes as well as macrophages ${ }^{43,44}$. Pathological conditions of anti-MDA5positive DM/CADM-ILD are complicated and require further determination. This may affect the diversity of elevated level of serum chitotriosidase and ferritin. Moreover, the range of serum ferritin levels was much greater (107-12701 ng/ml) than chitotriosidase levels (0-53.2 ng/ml). Further, our study population was relatively small, which may have influenced the results of our statistical analyses. Because both serum chitotriosidase and ferritin levels were higher in the nonsurvivor group than the survivor group, further investigations are warranted to validate the correlation between serum chitotriosidase levels and serum ferritin levels in anti-MDA5-positive DM/CADM-ILD.

KL-6, a glycoprotein secreted by type II alveolar pneumocytes and bronchiolar epithelial cells, has been identified as a serum biomarker for monitoring a variety of ILD conditions, including PM/DM-ILD ${ }^{45,46,47}$; however, its prognostic value in patients with anti-MDA5-positive DM/CADM-ILD

Personal non-commercial use only. The Journal of Rheumatology Copyright $\odot$ 2019. All rights reserved. 
has not been evaluated. In our study, we showed that KL-6 levels were higher in the nonsurvivor group than in the survivor group and that KL-6 levels $\geq 720 \mathrm{U} / \mathrm{ml}$ were associated with a poor prognosis. On comparing chitotriosidase, ferritin, and KL-6 as prognostic biomarkers in patients with anti-MDA5-positive DM/CADM-ILD, we found that the AUC of serum chitotriosidase was larger than those of serum ferritin and KL-6, and the AIC index of chitotriosidase model was lower than those of ferritin and KL-6 models. This suggests that serum chitotriosidase is a better prognostic predictor in patients with anti-MDA5-positive DM/CADM-ILD. Large-scale prospective observational studies are warranted to validate prognostic significance of serum markers in patients with anti-MDA5-positive DM/CADM-ILD.

Our study had several limitations. First, the number of study patients was small. Because of the small sample size (10 deaths among 30 patients), the findings of the multivariate analysis involving survival should be carefully interpreted. Second, the treatment regimen was not consistent among the study patients. The frequency of combination therapy, including corticosteroids, calcineurin inhibitors (cyclosporine or tacrolimus), and IV CYC, was higher in the nonsurvivor group than in the survivor group, suggesting that the disease activity among patients in the nonsurvivor group was severe although intensive treatments were administered. Finally, this study was retrospective, and the observation period varied among the patients. Studies have demonstrated the utility of new potential biomarkers, such as serum progranulin, serum YKL-40, and soluble CD163 $3^{48,49,50}$, in patients with PM/DMILD; however, all those studies were retrospective with a relatively small number of patients. Larger prospective studies are needed to further assess the prognostic factors and validate the prognostic significance of serum chitotriosidase in patients with anti-MDA5-positive DM/CADM-ILD.

We found that a high serum chitotriosidase level at the time of diagnosis was significantly associated with a poor outcome in patients with anti-MDA5-positive DM/CADM-ILD. Using the optimal cutoff levels of serum chitotriosidase, ferritin, and KL-6, we showed that these markers could predict a poor prognosis. The AUC of serum chitotriosidase was larger than the AUC of serum ferritin and KL-6. Further, serum chitotriosidase levels were correlated with oxygenation impairment and lung function, suggesting that serum chitotriosidase may be a promising noninvasive prognostic biomarker in patients with anti-MDA5-positive DM/CADM-ILD.

\section{ACKNOWLEDGMENT}

The authors thank C. Karasawa and Y. Morita from Medical and Biological Laboratory Co. Ltd., Tokyo, Japan, for assistance in the measurement of serum chitotriosidase levels. The authors also thank Dr. Kazutaka Mori from the Department of Respiratory Medicine, Shizuoka City Shimizu Hospital, Shizuoka, Japan, for his assistance in statistical analyses.

\section{ONLINE SUPPLEMENT}

Supplementary material accompanies the online version of this article.

\section{REFERENCES}

1. Ernste FC, Reed AM. Idiopathic inflammatory myopathies: current trends in pathogenesis, clinical features, and up-to-date treatment recommendations. Mayo Clin Proc 2013;88:83-105.

2. Sontheimer RD. Would a new name hasten the acceptance of amyopathic dermatomyositis (dermatomyositis sine myositis) as a distinctive subset within the idiopathic inflammatory dermatomyopathies spectrum of clinical illness? J Am Acad Dermatol 2002;46:626-36.

3. Gerami P, Schope JM, McDonald L, Walling HW, Sontheimer RD. A systematic review of adult-onset clinically amyopathic dermatomyositis (dermatomyositis sine myositis): a missing link within the spectrum of the idiopathic inflammatory myopathies. J Am Acad Dermatol 2006;54:597-613.

4. Fujisawa T, Suda T, Nakamura Y, Enomoto N, Ide K, Toyoshima M, et al. Differences in clinical features and prognosis of interstitial lung diseases between polymyositis and dermatomyositis. J Rheumatol 2005;32:58-64.

5. Suda T, Fujisawa T, Enomoto N, Nakamura Y, Inui N, Naito T, et al. Interstitial lung diseases associated with amyopathic dermatomyositis. Eur Respir J 2006;28:1005-12.

6. Fujisawa T, Hozumi H, Kono M, Enomoto N, Hashimoto D, Nakamura Y, et al. Prognostic factors for myositis-associated interstitial lung disease. PLoS One 2014;9:e98824.

7. Cottin V, Thivolet-Bejui F, Reynaud-Gaubert M, Cadranel J, Delaval P, Ternamian PJ, et al. Interstitial lung disease in amyopathic dermatomyositis, dermatomyositis and polymyositis. Eur Respir J 2003;22:245-50.

8. Connors GR, Christopher-Stine L, Oddis CV, Danoff SK. Interstitial lung disease associated with the idiopathic inflammatory myopathies: what progress has been made in the past 35 years? Chest 2010;138:1464-74

9. Marie I, Hatron PY, Dominique S, Cherin P, Mouthon L, Menard JF. Short-term and long-term outcomes of interstitial lung disease in polymyositis and dermatomyositis: a series of 107 patients. Arthritis Rheum 2011;63:3439-47.

10. Lega JC, Reynaud Q, Belot A, Fabien N, Durieu I, Cottin V. Idiopathic inflammatory myopathies and the lung. Eur Respir Rev 2015;24:216-38.

11. Rider LG, Miller FW. Deciphering the clinical presentations, pathogenesis, and treatment of the idiopathic inflammatory myopathies. JAMA 2011;305:183-90.

12. Betteridge $\mathrm{Z}, \mathrm{McHugh} \mathrm{N}$. Myositis-specific autoantibodies: an important tool to support diagnosis of myositis. J Intern Med 2016;280:8-23.

13. Sato S, Hoshino K, Satoh T, Fujita T, Kawakami Y, Fujita T, et al. RNA helicase encoded by melanoma differentiation-associated gene 5 is a major autoantigen in patients with clinically amyopathic dermatomyositis: Association with rapidly progressive interstitial lung disease. Arthritis Rheum 2009;60:2193-200.

14. Nakashima R, Imura Y, Kobayashi S, Yukawa N, Yoshifuji H, Nojima T, et al. The RIG-I-like receptor IFIH1/MDA5 is a dermatomyositis-specific autoantigen identified by the anti-CADM-140 antibody. Rheumatology 2010;49:433-40.

15. Sato S, Murakami A, Kuwajima A, Takehara K, Mimori T, Kawakami A, et al. Clinical utility of an enzyme-linked immunosorbent assay for detecting anti-melanoma differentiation-associated gene 5 autoantibodies. PLoS One 2016;11:e0154285.

16. Gono T, Sato S, Kawaguchi Y, Kuwana M, Hanaoka M, Katsumata Y, et al. Anti-MDA5 antibody, ferritin and IL-18 are useful for the evaluation of response to treatment in interstitial lung disease with anti-MDA5 antibody-positive dermatomyositis. Rheumatology 2012;51:1563-70.

17. Hozumi H, Fujisawa T, Nakashima R, Johkoh T, Sumikawa H,

Personal non-commercial use only. The Journal of Rheumatology Copyright @ 2019 . All rights reserved. 
Murakami A, et al. Comprehensive assessment of myositis-specific autoantibodies in polymyositis/dermatomyositis-associated interstitial lung disease. Respir Med 2016;121:91-9.

18. Nakashima R, Hosono Y, Mimori T. Clinical significance and new detection system of autoantibodies in myositis with interstitial lung disease. Lupus 2016;25:925-33.

19. Moghadam-Kia S, Oddis CV, Sato S, Kuwana M, Aggarwal R. Antimelanoma differentiation-associated gene 5 antibody: expanding the clinical spectrum in North American patients with dermatomyositis. J Rheumatol 2017;44:319-25.

20. Hollak CE, van Weely S, van Oers MH, Aerts JM. Marked elevation of plasma chitotriosidase activity. A novel hallmark of Gaucher disease. J Clin Invest 1994;93:1288-92.

21. Kanneganti M, Kamba A, Mizoguchi E. Role of chitotriosidase (chitinase 1) under normal and disease conditions. J Epithel Biol Pharmacol 2012;5:1-9.

22. Boot RG, Renkema GH, Strijland A, van Zonneveld AJ, Aerts JM. Cloning of a cDNA encoding chitotriosidase, a human chitinase produced by macrophages. J Biol Chem 1995;270:26252-6.

23. Cakir G, Gumus S, Ucar E, Kaya H, Tozkoparan E, Akgul EO, et al. Serum chitotriosidase activity in pulmonary tuberculosis: response to treatment and correlations with clinical parameters. Ann Lab Med 2012;32:184-9.

24. Harlander M, Salobir B, Zupancic M, Dolensek M, Bavcar Vodovnik T, Tercelj M. Serial chitotriosidase measurements in sarcoidosis - two to five year follow-up study. Respir Med 2014; 108:775-82.

25. Letuve S, Kozhich A, Humbles A, Brewah Y, Dombret MC, Grandsaigne $\mathrm{M}$, et al. Lung chitinolytic activity and chitotriosidase are elevated in chronic obstructive pulmonary disease and contribute to lung inflammation. Am J Pathol 2010;176:638-49.

26. James AJ, Reinius LE, Verhoek M, Gomes A, Kupczyk M, Hammar $\mathrm{U}$, et al. Increased YKL-40 and chitotriosidase in asthma and chronic obstructive pulmonary disease. Am J Respir Crit Care Med 2016;193:131-42.

27. Cho SJ, Weiden MD, Lee CG. Chitotriosidase in the pathogenesis of inflammation, interstitial lung diseases and COPD. Allergy Asthma Immunol Res 2015;7:14-21.

28. Gono T, Miyake K, Kawaguchi Y, Kaneko H, Shinozaki M, Yamanaka H. Hyperferritinaemia and macrophage activation in a patient with interstitial lung disease with clinically amyopathic DM. Rheumatology 2012;51:1336-8.

29. Bohan A, Peter JB. Polymyositis and dermatomyositis (first of two parts). N Engl J Med 1975;292:344-7.

30. Hozumi H, Enomoto N, Kono M, Fujisawa T, Inui N, Nakamura Y, et al. Prognostic significance of anti-aminoacyl-tRNA synthetase antibodies in polymyositis/dermatomyositis-associated interstitial lung disease: a retrospective case control study. PLoS One 2015;10:e0120313.

31. Collard HR, Ryerson CJ, Corte TJ, Jenkins G, Kondoh Y, Lederer DJ, et al. Acute exacerbation of idiopathic pulmonary fibrosis. An international working group report. Am J Respir Crit Care Med 2016;194:265-75.

32. Fujisawa T, Hozumi H, Kono M, Enomoto N, Nakamura Y, Inui N, et al. Predictive factors for long-term outcome in polymyositis/dermatomyositis-associated interstitial lung diseases. Respir Investig 2017;55:130-7.

33. American Thoracic Society. Idiopathic pulmonary fibrosis: diagnosis and treatment. International consensus statement. American Thoracic Society (ATS), and the European Respiratory Society (ERS). Am J Respir Crit Care Med 2000;161:646-64.

34. Raghu G, Collard HR, Egan JJ, Martinez FJ, Behr J, Brown KK, et al. An official ATS/ERS/JRS/ALAT statement: idiopathic pulmonary fibrosis: evidence-based guidelines for diagnosis and management. Am J Respir Crit Care Med 2011;183:788-824.

35. Di Rosa M, Musumeci M, Scuto A, Musumeci S, Malaguarnera L. Effect of interferon-gamma, interleukin-10, lipopolysaccharide and tumor necrosis factor-alpha on chitotriosidase synthesis in human macrophages. Clin Chem Lab Med 2005;43:499-502.

36. Malaguarnera L, Musumeci M, Di Rosa M, Scuto A, Musumeci S Interferon-gamma, tumor necrosis factor-alpha, and lipopolysaccharide promote chitotriosidase gene expression in human macrophages. J Clin Lab Anal 2005;19:128-32.

37. Lee CG, Herzog EL, Ahangari F, Zhou Y, Gulati M, Lee CM, et al. Chitinase 1 is a biomarker for and therapeutic target in scleroderma-associated interstitial lung disease that augments TGF-beta1 signaling. J Immunol 2012;189:2635-44.

38. van Eijk M, Scheij SS, van Roomen CP, Speijer D, Boot RG, Aerts JM. TLR- and NOD2-dependent regulation of human phagocyte-specific chitotriosidase. FEBS Lett 2007;581:5389-95.

39. Schulert GS, Grom AA. Pathogenesis of macrophage activation syndrome and potential for cytokine- directed therapies. Annu Rev Med 2015;66:145-59.

40. Ruscitti P, Cipriani P, Di Benedetto P, Liakouli V, Carubbi F, Berardicurti $\mathrm{O}$, et al. Advances in immunopathogenesis of macrophage activation syndrome during rheumatic inflammatory diseases: toward new therapeutic targets? Expert Rev Clin Immunol 2017; 13:1041-7.

41. Sakai M, Kubota T, Ohnishi H, Yokoyama A. A novel lung injury animal model using KL-6-measurable human MUC1-expressing mice. Biochem Biophys Res Commun 2013;432:460-5.

42. Fujiki $Y$, Kotani T, Isoda $\mathrm{K}$, Ishida $\mathrm{T}$, Shoda $\mathrm{T}$, Yoshida $\mathrm{S}$, et al. Evaluation of clinical prognostic factors for interstitial pneumonia in anti-MDA5 antibody-positive dermatomyositis patients. Mod Rheumatol 2018;28:133-40.

43. Hintze KJ, Theil EC. Cellular regulation and molecular interactions of the ferritins. Cell Mol Life Sci 2006;63:591-600.

44. Cohen LA, Gutierrez L, Weiss A, Leichtmann-Bardoogo Y, Zhang DL, Crooks DR, et al. Serum ferritin is derived primarily from macrophages through a nonclassical secretory pathway. Blood 2010;116:1574-84

45. Ishikawa N, Hattori N, Yokoyama A, Kohno N. Utility of KL-6/MUC1 in the clinical management of interstitial lung diseases. Respir Investig 2012;50:3-13.

46. Fathi M, Barbasso Helmers S, Lundberg IE. KL-6: a serological biomarker for interstitial lung disease in patients with polymyositis and dermatomyositis. J Intern Med 2012;271:589-97.

47. Arai S, Kurasawa K, Maezawa R, Owada T, Okada H, Fukuda T. Marked increase in serum KL-6 and surfactant protein D levels during the first 4 weeks after treatment predicts poor prognosis in patients with active interstitial pneumonia associated with polymyositis/dermatomyositis. Mod Rheumatol 2013;23:872-83

48. Tanaka A, Tsukamoto H, Mitoma H, Kiyohara C, Ueda N, Ayano M, et al. Serum progranulin levels are elevated in dermatomyositis patients with acute interstitial lung disease, predicting prognosis. Arthritis Res Ther 2015;17:27.

49. Hozumi H, Fujisawa T, Enomoto N, Nakashima R, Enomoto Y, Suzuki Y, et al. Clinical utility of YKL-40 in polymyositis/ dermatomyositis-associated interstitial lung disease. J Rheumatol 2017;44:1394-401.

50. Enomoto Y, Suzuki Y, Hozumi H, Mori K, Kono M, Karayama M, et al. Clinical significance of soluble CD163 in polymyositis-related or dermatomyositis-related interstitial lung disease. Arthritis Res Ther 2017;19:9. 